\title{
Reagrupación familiar de menores en Aragón. Propuestas de acompañamiento en el proceso migratorio
}

\author{
Chabier Gimeno-Monterde \\ Diplomado en Trabajo Social. Doctor en Sociología \\ Universidad de Zaragoza. Zaragoza, España \\ https://orcid.org/0000-0002-5746-1372 $・$ chabierg@unizar.es \\ José David Gutiérrez-Sánchez \\ Trabajador Social. Doctor en Sociología \\ Universidad Pablo de Olavide. Sevilla, España \\ https://orcid.org/0000-0003-0670-5426 • jdgutsan@upo.es
}

\section{Resumen}

La reagrupación familiar es una de las vías de migración legal más frecuentes, también entre los menores de edad, recayendo sobre las administraciones locales la responsabilidad de ofrecer políticas de integración de estos niños y adolescentes. Esta investigación propone la transferencia de programas exitosos en esta tarea. Para ello, aborda el diagnóstico de este proceso migratorio en un territorio, a través de dos vías: el análisis cuantitativo de los registros públicos y la categorización de las necesidades detectadas en los servicios sociales, mediante entrevistas y análisis de expedientes. Los resultados señalan la existencia de tensiones derivadas de factores asociados, por un lado, al proceso migratorio y a la reconfiguración de la estructura familiar; y, por otro, a la organización de los servicios públicos que atienden a las familias. Concluimos que, con el fin de promover un itinerario de integración en la sociedad de acogida, son necesarias estrategias preventivas, articuladas como programas de acompañamiento.

Palabras clave: Migración; Reagrupación familiar; Acompañamiento social; Menores; Política migratoria; Integración social.

Recibido: 23/09/2019 | Aprobado: 18/11/2019

(1) (2) Esta obra está bajo una Licencia Creative Commons Atribución-NoComercial-CompartirIgual 4.0 Internacional.

Financiación o proveniencia del artículo: Contrato de investigación 2018/0204 “Diseño de un programa de acompañamiento en la reagrupación familiar de menores" avalado por la Dirección General de Igualdad y Familias del Departamento de Ciudadanía y Derechos Sociales (Gobierno de Aragón, España).

¿Cómo citar este artículo? / How to quote this article?

Gimeno-Monterde, C., y Gutiérrez-Sánchez, J.D. (2020). Reagrupación familiar de menores en Aragón. Propuestas de acompañamiento en el proceso migratorio. Prospectiva. Revista de Trabajo Social e intervención social, (29), 151-172. doi: 10.25100/ prts.v0i29.8542. 


\title{
Family reunification of minors in Aragón. Proposals to accompany the migratory process
}

\begin{abstract}
Family reunification is one of the most frequent legal migration routes, also among minors. The responsibility of offering integration policies for these children and adolescents falls on local authorities. This research proposes the transfer of successful programs in this task. For this, it addresses the diagnosis of this migratory process in a territory, through two ways: a quantitative analysis of public data and the categorization of needs detected in social services, through interviews and file analysis. The results indicate the existence of tensions derived from factors related, on the one hand, to the migratory process and to the reconfiguration of the family structure; and, on the other, to the organization of public services that serve families. We conclude that, in order to promote an integration itinerary in the host society, preventive strategies are necessary, articulated as accompaniment programs.

Keywords: Migration; Family reunification; Social accompaniment; Minors; Migration policy; Social Integration.

Sumario: 1. Introducción, 2. La reagrupación de menores en España, 3. Metodología, 4. Hallazgos, 4.1 Familias y menores: aproximación a los retos de integración, 4.2. Implicaciones para las políticas públicas, 5. Conclusiones, 6. Referencias bibliográficas.
\end{abstract}




\section{Introducción}

La situación de los menores que son reagrupados por sus familias, migradas a la Unión Europea, refleja las contradicciones del actual régimen de fronteras (Shamir, 2005). La vulnerabilidad que generan en la infancia y la adolescencia migrante estas estrategias estatales desencadena respuestas familiares tanto dentro, como en los márgenes de la ley: este es el caso de algunos perfiles de menores que migran solos, para eludir las limitaciones impuestas por las categorías de reagrupación familiar promovidas por el Norte Global (Gil, 2010). Ambos, adultos y jóvenes, comparecen ante los controles fronterizos respondiendo al deseo contemporáneo y globalizado de acceder a unos servicios básicos que los países de origen les niegan biográficamente (Vacchiano, 2018). Pero, en lugar de adaptarse a esta consolidación de los flujos en todo el planeta, los estados intentan mantener su autoridad, no sólo sobre las movilidades, sino también sobre sus vínculos familiares. En una Europa que se percibe en constante cambio, el control sobre el movimiento de personas y su potencial movilidad, se ha convertido en una preocupación central para los proyectos de biopolítica y gubernamentalidad (Glick \& Salazar, 2013).

Este artículo subraya la importancia del enfoque preventivo en el Trabajo Social con la infancia migrante que desarrollan las políticas sociales locales. Estas están destinadas a su integración, entendida como la adaptación mutua entre los menores reagrupados y la sociedad de acogida, que debe aceptar e incorporar cambios normativos e institucionales (Malgesini y Giménez, 1997). En el contexto europeo es en este nivel de la Administración donde se afronta este reto, mientras que los Estados se limitan al control de fronteras y a las directrices más generales sobre las políticas de acogida. Así, la investigación descrita señala la posibilidad de colaborar y transferir entre regiones o municipios buenas prácticas exitosas, mediante la implementación de programas específicos.

En primer lugar, se presenta la situación de este proceso migratorio en España. En segundo lugar, se aborda esta situación y las consiguientes tensiones en una Comunidad Autónoma. Analizando en último lugar las implicaciones que esto supone para las políticas sociales locales y proponiendo medidas de mejora.

\section{La reagrupación de menores en España}

En Europa el estudio de las migraciones de menores incluye a las familias que migran con sus descendientes, a los adolescentes que migran autónomamente o, como es nuestro caso, a aquellos que habiendo nacido fuera de este territorio, se asientan posteriormente en él. Esta "generación una y media" (Aparicio y Tornos, 2006), surge por procedimientos de reagrupación familiar orientados a un modelo de familia nuclear, heterosexual y monógamo (Mestre, 2005, p. 158); en el que la mujer es concebida en algunas leyes nacionales como esposa y madre, no siéndole concedida la autorización de trabajo al mismo tiempo que la de residencia (Quintero y Fernández, 2014). Las perspectivas críticas con una concepción homogénea de este proceso migratorio, así como de las propias familias de origen migrante (Guerraoui \& Sturm, 2012), subrayan el carácter lineal y mecanicista que se adopta tanto por

Prospectiva. Revista de Trabajo Social e intervención social • No. $29 \bullet$ ene.-jun. $2020 \bullet$ pp. 151-172 e-ISSN: 2389-993X • Doi: 10.25100/ prts.v0i29.8542

Universidad del Valle - Cali, Colombia 
Gimeno-Monterde y Gutiérrez-Sánchez

algunas ciencias sociales, como por la propia legislación migratoria. Estos paradigmas postcoloniales proponen la migración familiar como un tránsito de la tradición a la modernidad, sinónimo de promoción y progreso, de una forma simplificada.

Desde una posición opuesta, otras perspectivas, como la feminista, muestran la complejidad de los grupos domésticos participantes en las migraciones, especialmente en las transnacionales, así como las profundas transformaciones que estas suponen para las familias, tanto nucleares como extensas (Pedone, Agrela y Gil, 2012). La reestructuración de las relaciones familiares implica cambios en las responsabilidades, tanto de adultos como de menores, nuevas formas de convivencia y, a veces también, la incorporación de nuevos miembros en destino. Cambios que involucran a todas las generaciones, en grupos domésticos presentes en varios países al mismo tiempo (Ramo y Meléndez, 2012).

Los niños, niñas y adolescentes reagrupados, protagonistas de este artículo, pasan en este proceso por hitos que configuran un reto multidimensional para su biografía: separándose de sus progenitores, conviviendo con familiares, redefiniendo su afectividad ante las distancias, en sus lugares de origen; pero también relacionándose con una nueva cultura, con nuevos roles de familiares y de género, entre otros cambios, en el país de destino (Novales, 2015). Este proceso no está, a menudo, exento de conflictos y contradicciones, que exigen una continua redefinición de los roles familiares, además de negociaciones y, en ocasiones, momentos de ruptura. Pues los menores que migran por reagrupación, al contrario que los adultos, carecen a menudo de un proyecto migratorio propio y bien definido, tomando su migración un cariz forzoso o de exilio: en el cruce entre dos edades, dos culturas y dos lealtades (Sayed, 2010). Todo ello en el marco de un nuevo mercado de trabajo globalizado, en el que las restricciones jurídicas del Norte Global limitan la libertad de movimiento y la unidad familiar (Hervías, 2014).

Constatando que la reagrupación familiar es la forma principal de migración legal hacia la Unión Europea entre los nacionales de terceros países, esta aprobó la Directiva 2003/86/CE que, junto a la legislación de los estados miembros, regula esta movilidad. Reconociendo como principio rector el derecho a la unidad de la familia, al entenderse que facilita una mayor cohesión social, la Directiva vincula la reagrupación familiar al derecho a la vida privada familiar, como derecho subjetivo, permitiendo que se solicite la autorización de residencia para determinados familiares que viven fuera de la UE: el o la cónyuge o pareja de hecho, los hijos e hijas menores de edad o con discapacidad y los ascendientes que dependan económicamente de las personas reagrupantes. El derecho a la reagrupación, además, se vincula a la duración de la autorización de residencia de las personas reagrupantes.

En el caso español, un estado receptor de migraciones internacionales durante el inicio del presente siglo, la ley vigente para la reagrupación familiar es la Ley Orgánica 2 de 2009, sobre derechos y libertades de los extranjeros en España y su integración social. Los artículos 16 a 19 se dedican a la reagrupación familiar, indicando el derecho a la reagrupación, cuáles 
son los familiares reagrupables, los requisitos necesarios, así como procedimientos y circunstancias especiales que puedan darse en la reagrupación familiar, siguiendo para ello el modelo normativo de familia (Pedone, 2008), aunque reconociendo ahora a las parejas de hecho, que quedan incluidas como relación de afectividad análoga a la conyugal, además de facilitar el acceso inmediato al mercado de trabajo, restringido por la legislación anterior (Hervías, 2014). En este sentido, las organizaciones humanitarias vienen proponiendo cambios en el articulado de esta ley, para evitar, entre otras actuaciones, la intervención de las oficinas consulares españolas en los países de origen, que, extralimitándose en sus competencias, realizan un control previo del grado de parentesco y del riesgo de persecución del familiar reagrupado; así como las restricciones a la reagrupación de familiares ascendientes (Foro para la Integración Social de los Inmigrantes - FISI, 2017). De hecho, las exigencias normativas de disponer de un alojamiento adecuado, seguro de enfermedad y de recursos económicos suficientes, han conducido durante la Gran Recesión a situaciones de riesgo social dentro de la familia reagrupante o entre la familia y su entorno (Novales, 2015), volviéndose a romper la unidad familiar en algunos casos (por retornos no deseados, etc.), en familias que no tienen los recursos suficientes para sostener a todos sus miembros (Moreno y De Alós, 2016).

En cuanto al volumen de las reagrupaciones de menores en España, el acceso a los registros estadísticos es complejo, como señalan estudios especializados (Domingo, León y García, 2009; González-Ferrer, 2009; 2014). Los diferentes ministerios responsables de esta misión durante el presente siglo, facilitan datos sobre el conjunto de las personas reagrupadas, sin apenas desagregación. Algo similar a lo que ocurre con los padrones municipales y los últimos Censos de Población y Viviendas (Blanco, 2016). Al margen de las estrategias familiares, difíciles de computar, en las que las llegadas a España por reagrupación pueden estar visibilizando a familiares que ya residían aquí y que recurren a esa vía de regularización (Pedone et al., 2012).

Esta debilidad en las fuentes de información sobre las personas reagrupadas es el reflejo de unas políticas públicas de acogida igualmente necesitadas de una revisión y actualización (ECRI, 2018), al estar construidas sobre la base del primer nivel de integración, focalizado en la participación en el mercado laboral (Moreno y De Alós, 2016). El impacto de la Gran Recesión en el empleo ha fragilizado especialmente a las personas migradas (Miguélez y López, 2014), poniendo en evidencia la necesidad de incidir sobre nuevos factores, como la integración de los descendientes, entre estos los jóvenes reagrupados, así como el necesario enfoque de género en las políticas a implementar. En esta línea, la principal aportación ha venido históricamente de los programas de las administraciones locales orientados a la integración de las familias migrantes, como el desaparecido Servicio de Mediación Social Intercultural de la Comunidad de Madrid (Giménez, 2004) y otras experiencias menos amplias (Pastor y Martínez, 2014). Estas han incluido intervenciones específicas de mediación familiar, asesoría en las solicitudes de reagrupación, etc. Con todo, es el Ayuntamiento de Barcelona el que ha desarrollado el programa específico más avanzado en sus objetivos y logros en este campo, con el servicio de Acompanyament al Reagrupament Familiar, que forma parte del Programa de Noves Famílies a Barcelona, puesto en marcha en el año 2006 (Brey \& Stanek, 2013; Díaz, Gómez \& Ricart, 2019). Este programa ha sido evaluado como buena práctica y se ha ampliado progresivamente a más distritos de la ciudad (Pedone, Gómez, Sardà \& Llobet, 2013).

Prospectiva. Revista de Trabajo Social e intervención social • No. $29 \bullet$ ene.-jun. 2020 • pp. 151-172 e-ISSN: 2389-993X • Doi: 10.25100/prts.v0i29.8542 Universidad del Valle - Cali, Colombia 


\section{Metodología}

El Gobierno de Aragón ${ }^{1}$ encargó en 2018 al área de Trabajo Social de la Universidad de Zaragoza la realización de un diagnóstico sobre la situación de los menores de edad reagrupados por sus familias². Así como el diseño de un programa de acompañamiento a progenitores y descendientes implicados en ese proceso migratorio. Para llevar a cabo el diagnóstico, el equipo planteó dos aproximaciones. Una cuantitativa, en la que solicitamos datos al Observatorio Permanente de las Migraciones (OPM); al Instituto Aragonés de Servicios Sociales (IASS); y al Ayuntamiento de Zaragoza, por concentrar esta ciudad al $50,9 \%$ de la población aragonesa. Este último nos facilitó información sobre solicitudes de asesoría en su servicio social especializado. Y el IASS datos anonimizados de los setenta y cinco expedientes del Sistema de Atención a la Infancia y la Adolescencia que afectaban entre 2017 y 2018 a menores reagrupados.

En cuanto a la aproximación cualitativa (Tabla 1), enfocada a determinar las necesidades y prioridades que perciben los profesionales que atienden a esta población desde la administración local, realizamos seis entrevistas estructuradas individuales, así como dos entrevistas grupales. La información recogida en ellas fue categorizada a través de Excel, definiendo así las tensiones sobre las que actuar con el programa cuyo diseño se nos requería. Un marco temporal y de financiación más amplio hubiera permitido, además, incorporar entrevistas a familias; constituyendo esta una limitación del diagnóstico desarrollado, que fue asumida por el ente público contratante.

Tabla 1. Entrevistas

\begin{tabular}{lll}
\hline Modalidad & Entidad & Participantes \\
\hline Grupal & Comarca Valdejalón & 5 trabajadoras sociales \\
& $\begin{array}{l}\text { Sistema de Atención a la Infancia y la Adolescencia } \\
\text { (Instituto Aragonés de Servicios Sociales) }\end{array}$ & $\begin{array}{l}\text { y técnicas } \\
\text { Individual }\end{array}$ \\
$\begin{array}{l}\text { Ayuntamiento de Zaragoza (servicios sociales } \\
\text { especializados) }\end{array}$ & Trabajadora social \\
& $\begin{array}{l}\text { Consejería de Sanidad (Gobierno de Aragón) } \\
\text { Centro Aragonés de Recursos para la Educación }\end{array}$ & Técnica \\
& $\begin{array}{l}\text { Técnica } \\
\text { Selusiva }\end{array}$ & Abogada \\
& $\begin{array}{l}\text { inmigrante (Colegio de Abogados de Zaragoza) } \\
\text { Equipo de Medio Abierto (Instituto Aragonés de }\end{array}$ & Coordinador \\
& $\begin{array}{l}\text { Servicios Sociales) } \\
\text { Fundación Adcara }\end{array}$ & Trabajadora social \\
\hline
\end{tabular}

Fuente: elaboración propia

${ }^{1}$ Agradecemos a la Dirección General de Igualdad y Familias del Departamento de Ciudadanía y Derechos Sociales el encargo de esta investigación. Y al personal del Instituto Aragonés de Servicios Sociales, a través del Sistema de Atención a la Infancia y la Adolescencia, su aportación de información sobre menores reagrupados atendidos en su Dirección Provincial de Zaragoza. Igualmente, agradecemos la colaboración del resto de profesionales y entidades que han participado.

2 El equipo contó con la experta en derecho migratorio Begoña Heras y, como personal en formación, con la trabajadora social Marisa Alcaraz.

Prospectiva. Revista de Trabajo Social e intervención social • No. $29 \bullet$ ene.jun. $2020 \bullet$ pp. 151-172 e-ISSN: 2389-993X • Doi: 10.25100/prts.v0i29.8542

Universidad del Valle - Cali, Colombia 
En una segunda parte, partiendo del análisis de los datos cuantitativos recogidos y de las entrevistas, elaboramos una propuesta inicial de programa de intervención. Contrastándola en una jornada de trabajo interinstitucional con el Àrea de Drets Socials, Participació i Transparència de la Direcció d'Atenció i Acollida a Immigrants del Ayuntamiento de Barcelona y personal técnico del Gobierno de Aragón. La propuesta gestada en este espacio se presentó en un grupo focal a seis trabajadoras sociales de tres comarcas: Bajo Aragón, Bajo Aragón-Caspe y Baix Cinca. Con las propuestas de mejora recogidas, se elaboró el informe final. El programa diseñado se pone en funcionamiento durante el año 2019 mediante una experiencia piloto en una comarca.

\section{Hallazgos}

\section{1 familias y menores: aproximación a los retos de integración}

De acuerdo al trabajo de campo que acabamos de describir, los resultados nos permiten aproximarnos a la reagrupación de menores extranjeros en una región sureuropea, por un lado, a través del perfil sociodemográfico de estos $\mathrm{y}$, por otro, a partir de las dificultades detectadas por los servicios sociales en las familias que activan esta modalidad migratoria.

\section{Características sociodemográficas de menores y familias}

En Aragón, de forma similar a otras Comunidades Autónomas, las características sociodemográficas del colectivo de menores reagrupados responden a dos situaciones administrativas. Por un lado, los servicios sociales locales, que intervienen en parte del proceso administrativo de la reagrupación, describen en sus informes un conglomerado conformado por familias de origen no comunitario, que se divide en tres grandes grupos: del África subsahariana, de América central y del sur y de otros estados con menor visibilidad para estos servicios (China y Pakistán). Siendo el volumen de estas reagrupaciones descendiente.

Por otro lado, constatamos que los estados miembros de la Unión Europea son el origen, a su vez, de más del doble de los menores llegados a Aragón para reunirse de nuevo con sus familias. Sin embargo, como veremos, no son objeto de políticas específicas que atiendan este proceso social. Algo que contrasta con el incremento constante del volumen de este colectivo, ligeramente masculinizado. Aunque ambos grupos de menores tienen diferente estatus jurídico, entendemos que estamos ante un proceso de reagrupación que, como los agentes entrevistados nos confirman, no difiere en lo social.

Si analizamos los datos facilitados por el Observatorio Permanente de la Inmigración español al Gobierno de Aragón, podemos precisar más esta primera imagen. Lo haremos comenzando por la población total reagrupada, tanto adulta como menor de edad, describiendo posteriormente más detalladamente esta última. En el año 2017, hubo en Aragón 4.270 personas reagrupadas por residentes que procedían de estados no comunitarios $^{3}$. Entre ellas, había un $57,7 \%$ de mujeres. Por tanto, las personas reagrupadas suponen casi un 7,0\% de la población no comunitaria residente (62.155). La evolución de

${ }^{3}$ Categorizados como "extranjeros con tarjeta de residencia en vigor".

Prospectiva. Revista de Trabajo Social e intervención social • No. $29 \bullet$ ene.-jun. 2020 • pp. 151-172 e-ISSN: 2389-993X • Doi: 10.25100/ prts.v0i29.8542

Universidad del Valle - Cali, Colombia 
Gimeno-Monterde y Gutiérrez-Sánchez

estas reagrupaciones marca una tendencia descendente (Tabla 2), con mayor presencia de mujeres, sobre todo adultas (Figura 1). En cuanto a la población residente en Aragón, nacional de un Estado miembro de la UE y de Estados parte del Acuerdo sobre el Espacio Económico Europeo ${ }^{4}$, esta ha aumentado su volumen de forma constante, entre 2013 y 2017: pasando de 105.003 a 121.288 personas respectivamente.

Tabla 2. Reagrupación de personas no comunitarias en Aragón (2009-2017).

\begin{tabular}{ccccccccc}
\hline 2009 & 2010 & 2011 & 2012 & 2013 & 2014 & 2015 & 2016 & 2017 \\
\hline 8.599 & 9.501 & 8.438 & 8.451 & 8.288 & 7.241 & 4.616 & 4.405 & 4.270
\end{tabular}

Fuente: Observatorio Permanente de la Inmigración

Figura 1. Reagrupación de personas no comunitarias en Aragón por sexo (2009-2017).

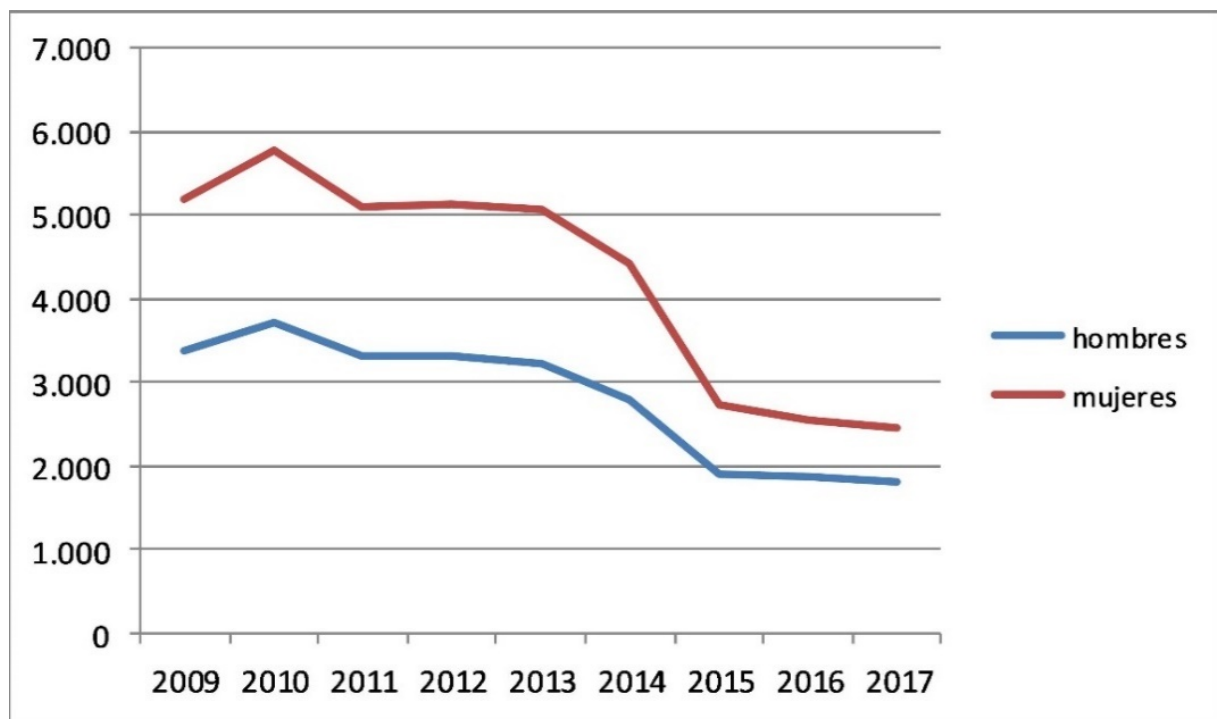

Fuente: Observatorio Permanente de la Inmigración.

Los datos registrados sobre menores de edad reagrupados, comunitarios o no, indican una evolución del flujo migratorio similar a la descrita para los adultos. En cuanto a los no comunitarios, el volumen ha descendido a menos de la mitad en siete años y, en conjunto, continúan reagrupándose más varones que mujeres (Figura 2). En el caso de los menores

${ }^{4}$ Alemania, Austria, Bélgica, Bulgaria, Chipre, Croacia, Dinamarca, Eslovaquia, Eslovenia, España, Estonia, Finlandia, Francia, Grecia, Hungría, Irlanda, Italia, Islandia, Letonia, Liechtenstein, Lituania, Luxemburgo, Malta, Noruega, Países Bajos, Polonia, Portugal, Reino Unido de Gran Bretaña e Irlanda del Norte, República Checa, Rumanía, Suecia y Suiza. 
comunitarios, si son nacionales de un Estado miembro de la UE, poseerán un Certificado de Registro; y si no lo son, poseerán una Tarjeta de Familiar de ciudadano de la UE. Según el OPM, la evolución ascendente de este grupo de menores se había estabilizado en 2017 con 10.904 registros (entre 0 y 15 años) ${ }^{5}$, de los que un 51,7\% son varones (Figura 3).

Figura 2. Menores de edad residentes en Régimen General en Aragón, que disponen de una autorización por reagrupación familiar en vigor a final de cada año y por sexo. Serie 2010-2017.

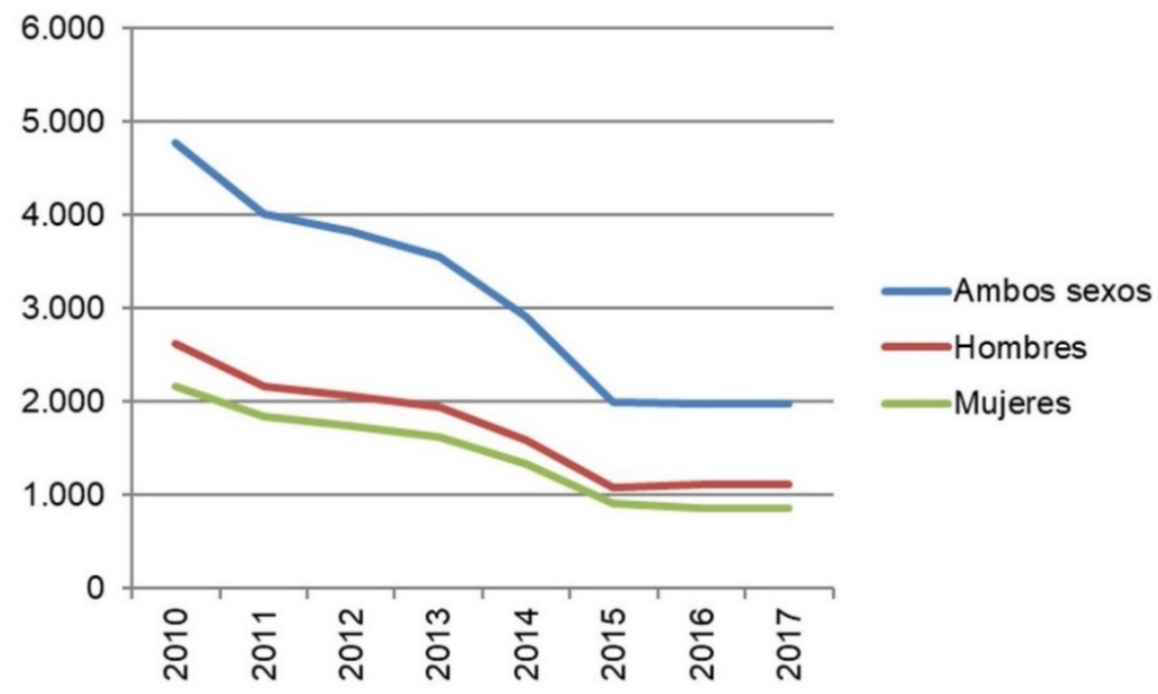

Fuente: Observatorio Permanente de la Inmigración.

Figura 3. Menores de edad (0-15 años) residentes en Aragón que disponen de certificado de registro o tarjeta de familiar de ciudadano de la Unión a final de cada año y por sexo. Serie 2009-2017.

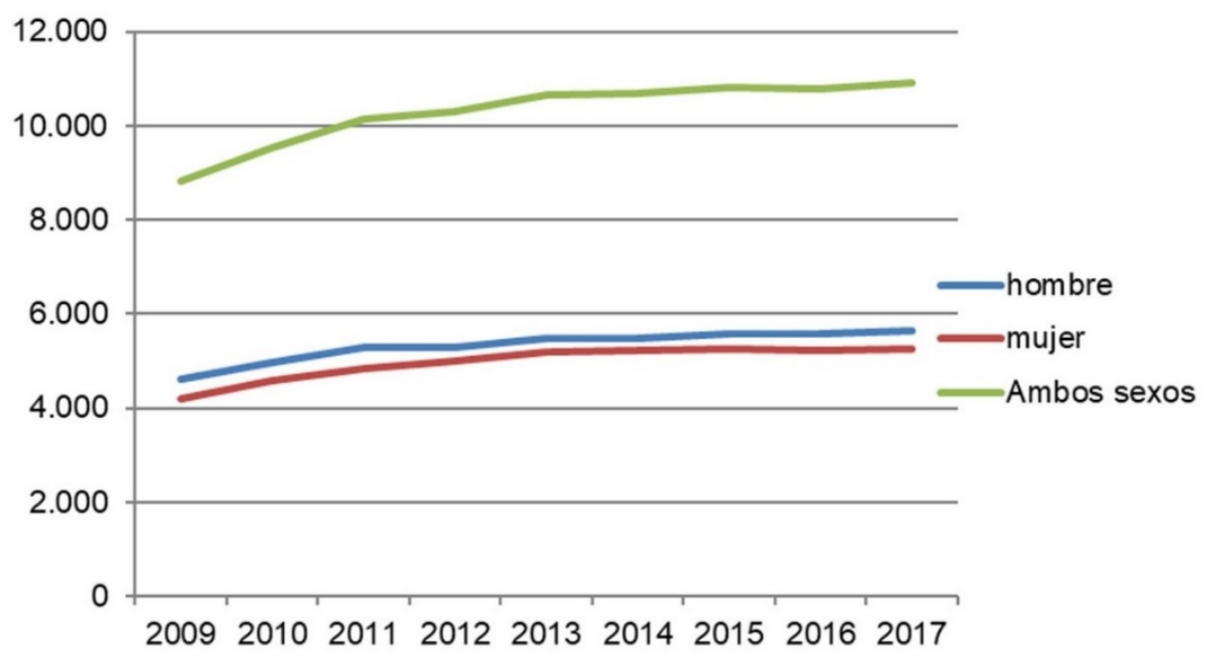

Fuente: Observatorio Permanente de la Inmigración.

${ }^{5}$ No se facilitaron datos para el tramo 16-17 años. 
Gimeno-Monterde y Gutiérrez-Sánchez

Para el año 2017, el OPM ofrecía también datos sociodemográficos sobre edad, sexo y nacionalidad, que nos permiten descender más en la precisión de los perfiles de esos 14.665 menores residentes en Aragón (Tabla 3), que disponían de una autorización por reagrupación como no comunitarios, o bien de un certificado de registro o una tarjeta de familiar de ciudadano de la Unión Europea. De estos últimos (76,7\%), la nacionalidad con más menores corresponde a Rumanía (64,5\%), y entre los no comunitarios $(13,0 \%)$, los orígenes se reparten entre Asia (2,7\%), África subsahariana (2,3\%), América central y del sur $(4,3 \%)$ y Magreb (3,7\%). Quedando, con un volumen muy inferior de menores registrados, un conjunto de países que suman el 10,3\% restante.

Estos datos también muestran una masculinización clara en los países del África subsahariana y el Magreb, así como en China y Pakistán (Figura 4). Aunque si tenemos en cuenta el sexo y la edad, también obtenemos una información muy similar a la procedente de los expedientes de familias cuyas dinámicas han propiciado una intervención de los servicios sociales especializados (IASS), como veremos en el apartado posterior.

Tabla 3. Menores de edad residentes en Aragón que disponen de una autorización por reagrupación, certificado de registro o tarjeta de familiar de ciudadano de la Unión por sexo y nacionalidad (31-12-2017).

\begin{tabular}{|c|c|c|c|}
\hline País & Total & Varones & Mujeres \\
\hline \multicolumn{4}{|c|}{ Comunitarios } \\
\hline Rumanía & 9.459 & 4.903 & 4.556 \\
\hline Bulgaria & 934 & 493 & 441 \\
\hline Polonia & 482 & 242 & 240 \\
\hline Portugal & 371 & 197 & 174 \\
\hline \multicolumn{4}{|c|}{ No comunitarios } \\
\hline Marruecos & 444 & 255 & 189 \\
\hline Nicaragua & 326 & 182 & 144 \\
\hline China & 252 & 149 & 103 \\
\hline República Dominicana & 170 & 86 & 84 \\
\hline Ecuador & 148 & 78 & 70 \\
\hline Pakistán & 137 & 90 & 47 \\
\hline Senegal & 129 & 81 & 48 \\
\hline Argelia & 100 & 43 & 57 \\
\hline Gambia & 82 & 63 & 19 \\
\hline Ghana & 78 & 39 & 39 \\
\hline Mali & 47 & 34 & 13 \\
\hline \multicolumn{4}{|c|}{ Otros } \\
\hline Resto de países & 1.506 & 766 & 740 \\
\hline
\end{tabular}

Fuente: Observatorio Permanente de la Inmigración.

Las edades de esta población se incrementan al mismo tiempo que avanzan las etapas escolares: con un $24,0 \%$ de menores en el periodo de la educación infantil, un $37,0 \%$ en primaria y un $39,0 \%$ en la secundaria. $Y$, en todas estas etapas, los varones tienen más 
presencia, también de forma creciente: con un 51,6\%, 52,2\% y 53,4\% respectivamente. Con todo, hay nacionalidades y edades en las que la masculinización es más significativa. Indicando pautas de reagrupación familiar muy influidas por los roles de género mayoritarios en el país de origen. El porcentaje de varones está por encima de la media de esta población, en todos los tramos de edad, en el caso de los menores magrebís. Pero sólo en ciertas etapas, y de forma muy marcada, en otras nacionalidades. En el África subsahariana, hay un 64,0\% de varones entre 6 y 11 años, y un 79,8\% entre 12 y 17 años. Esta masculinización aumenta si comparamos la zona occidental (Mali, Senegal, Gambia), donde apenas hay un 15,4\% de mujeres de esa edad, con un país más al sur, como Ghana, con un $45,0 \%$.

Algo semejante ocurre si desagregamos los datos de los estados asiáticos más representativos, Pakistán y China. Las cifras totales indican una mayor presencia de varones reagrupados, pero existen diferencias por edades. El colectivo de menores pakistanís está más masculinizado que la media general en educación infantil y en secundaria: $66,0 \%$ y $80,5 \%$. Y en el caso chino, durante la secundaria los varones alcanzan un $68,4 \%$ en su rango de edad; pero las mujeres llegan al $51,0 \%$ en la primaria. La pauta migratoria, en estos dos casos, puede estar relacionada con el peso relativo de cada sexo en cada grupo de edad. Las menores pakistanís mayores de 12 años sólo suponen un 6,0\% de esta población, mientras los varones de esa edad son un 24,0\%: señalando que la diáspora remite a las mujeres a Pakistán en torno a esa etapa. De forma similar, las menores chinas llegan también a Europa mayoritariamente a partir de los 6 años, según los datos recogidos.

Figura 4. Menores de edad residentes en Aragón que disponen de una autorización por reagrupación, certificado de registro o tarjeta de familiar de ciudadano de la Unión por sexo, edad agrupada y nacionalidad agrupada (31-12-2017).

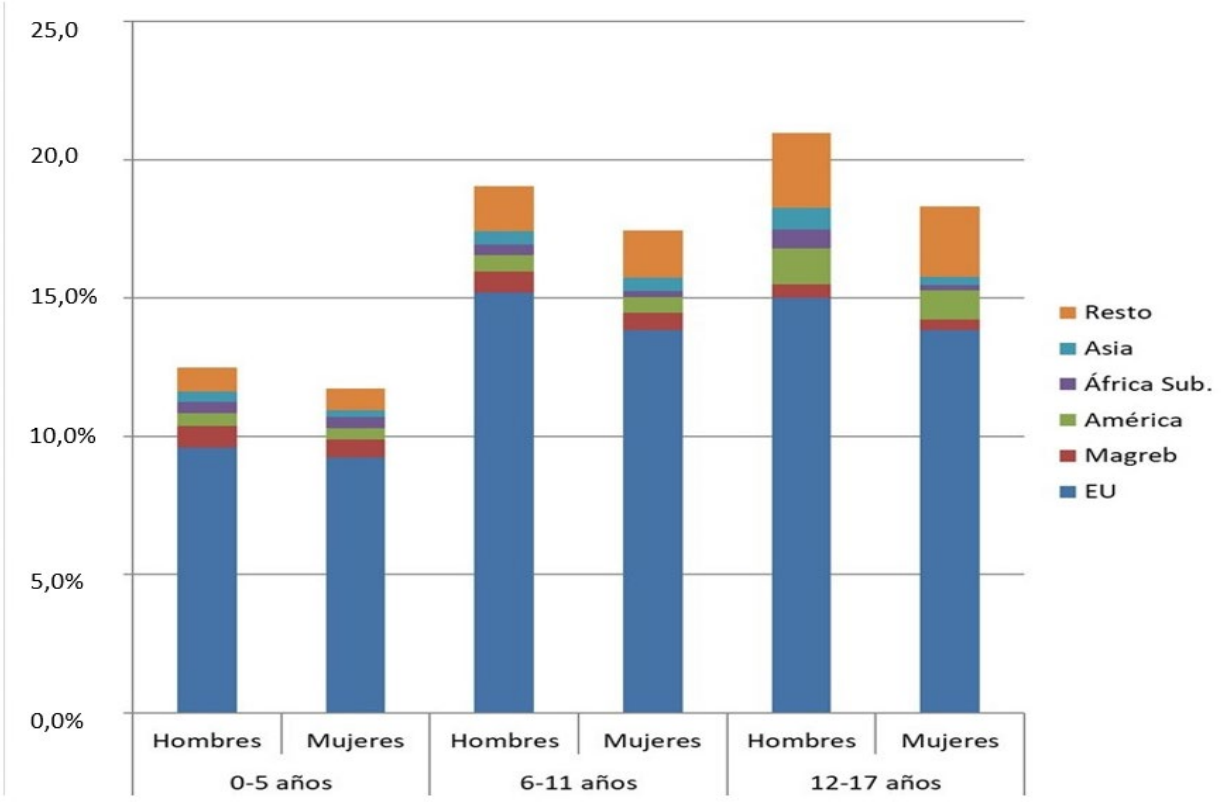

Fuente: Observatorio Permanente de la Inmigración. 
Gimeno-Monterde y Gutiérrez-Sánchez

Estos datos sobre las características sociodemográficas del colectivo de menores reagrupados pueden enriquecerse también con los procedentes de los servicios sociales locales, que elaboran los informes sobre adecuación de vivienda, dentro del proceso administrativo enmarcado por la actual legislación sobre extranjería. Para la ciudad de Zaragoza, contamos con información sobre los 640 expedientes tramitados en los Servicios Sociales especializados del Ayuntamiento en esas fechas: la mayoría de ellos fueron favorables (579 expedientes).

Coincidiendo con los datos a nivel autonómico sobre reagrupación de personas no comunitarias (f 1), este Ayuntamiento constata que desde el año 2007, momento de mayor número de consultas sobre reagrupación, estas han ido descendiendo, aunque se mantienen estables desde 2013 (Tabla 4).

Tabla 4. Informes sobre adecuación de vivienda en Zaragoza.

\begin{tabular}{rrrrrrr}
\hline año & 2011 & 2012 & 2013 & 2014 & 2015 & 2016 \\
\hline informes & 986 & 700 & 625 & 567 & 630 & 640
\end{tabular}

Fuente: Ayuntamiento de Zaragoza.

En cuanto a los menores reagrupados, los datos de Zaragoza (Figura 5) coinciden con las tendencias en otras ciudades de igual o superior tamaño (Sánchez, 2018). La presencia de dos orígenes con escasa participación en programas de atención a familias reagrupantes en esas mismas ciudades (China y Pakistán) suma un 20,0\%. Un tercio de los menores provienen del África Subsahariana y un cuarto de Latinoamérica.

Figura 5. Orígenes de menores reagrupables, porcentaje (Zaragoza).

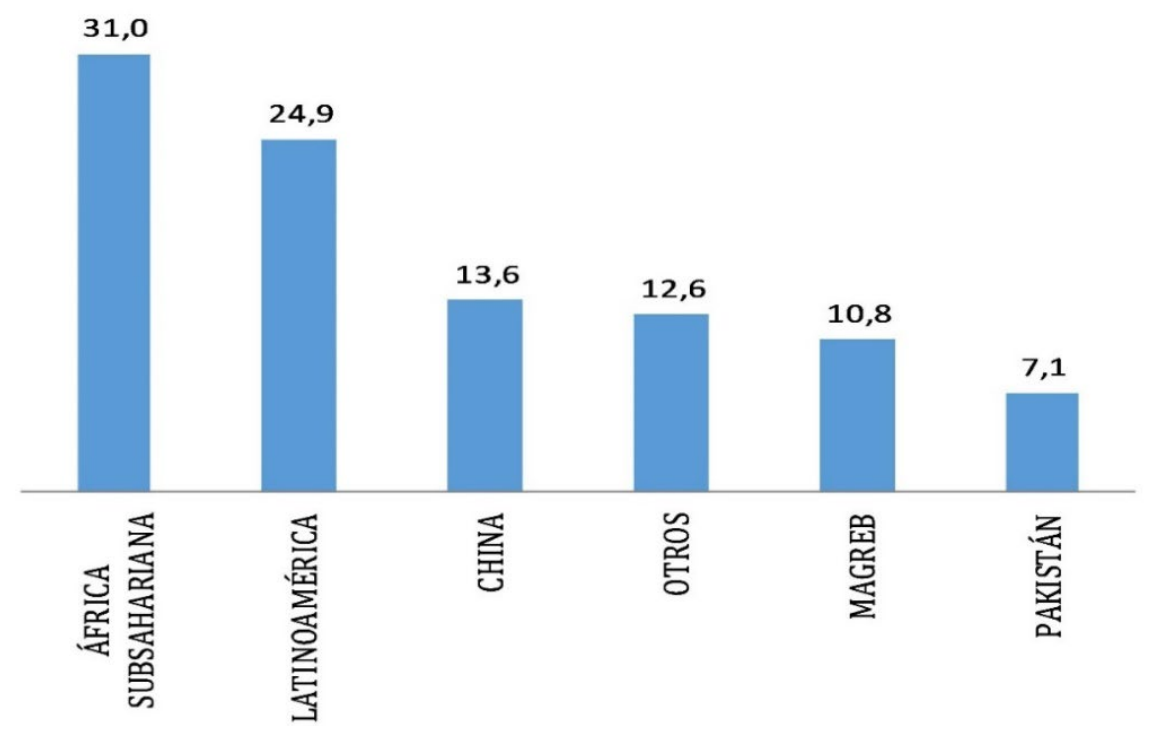

Fuente: Ayuntamiento de Zaragoza. 


\section{El sistema de protección de menores y la reagrupación}

Continuando la caracterización de la reagrupación de menores extranjeros, el trabajo de campo también nos permite describir las dificultades y tensiones propias de esta modalidad migratoria, que han motivado la intervención de los servicios sociales especializados en la protección de la infancia y la adolescencia. De forma que podamos establecer los factores de riesgo para los menores que fueron reagrupados. Estos resultados sobre menores en protección se complementan con una breve descripción sobre algunos expedientes del Equipo de Medio Abierto del IASS, responsable de la atención a los menores que han cometido infracciones jurídicas.

Comenzando por sus características sociodemográficas, entre los menores de edad reagrupados atendidos por el IASS hay un 6,0\% más de varones y proceden de tres continentes: Europa (36,5\%), América (36,5\%) y África (19,7\%). Sólo un menor provenía de Asia central.

En el momento de su reagrupación, la mitad de los menores atendidos posteriormente en el IASS tenían menos de 6 años de edad (55,2\%). Y uno de cada cuatro (26,9\%) estaba en edad de la Educación Primaria, de 6 a 12 años. De forma que más de dos terceras partes llegaron a Aragón antes del periodo de escolarización en Educación Secundaria (de 12 a 16 años). La intervención en los inicios de la etapa escolar, según estos datos, resulta clave. Especialmente si tenemos en cuenta que las reagrupaciones a edades tempranas aumentan, con el objetivo explícito de aminorar las dificultades con el idioma, etc., vinculándose implícitamente a la feminización de los cuidados (Ramo y Meléndez, 2012).

En cuanto a la intervención asistencial del IASS, esta comenzó mayoritariamente cuando los menores llegaron a la adolescencia. La mitad de los expedientes se refieren a mayores de 12 años (en Educación Secundaria) y uno de cada cinco en edad de educación postobligatoria. Este último grupo coincide con el que los diagnósticos en otras Comunidades Autónomas señalan como el de mayor riesgo de exclusión social (Pedone et al., 2013; FISI, 2017). La labor preventiva, por tanto, debería abarcar los primeros años de la estancia del menor en el país de destino (Figura 6), priorizando los años previos a la adolescencia. En esos primeros años de la migración, de gran influencia en el futuro de la integración en destino (González-Ferrer, 2009), más de la mitad de los expedientes $(55,2 \%)$ reflejan algún conflicto familiar que deriva en una intervención especializada por el SAIA. 
Gimeno-Monterde y Gutiérrez-Sánchez

Figura 6. Estancia en España hasta inicio de expediente en SAIA, porcentaje.

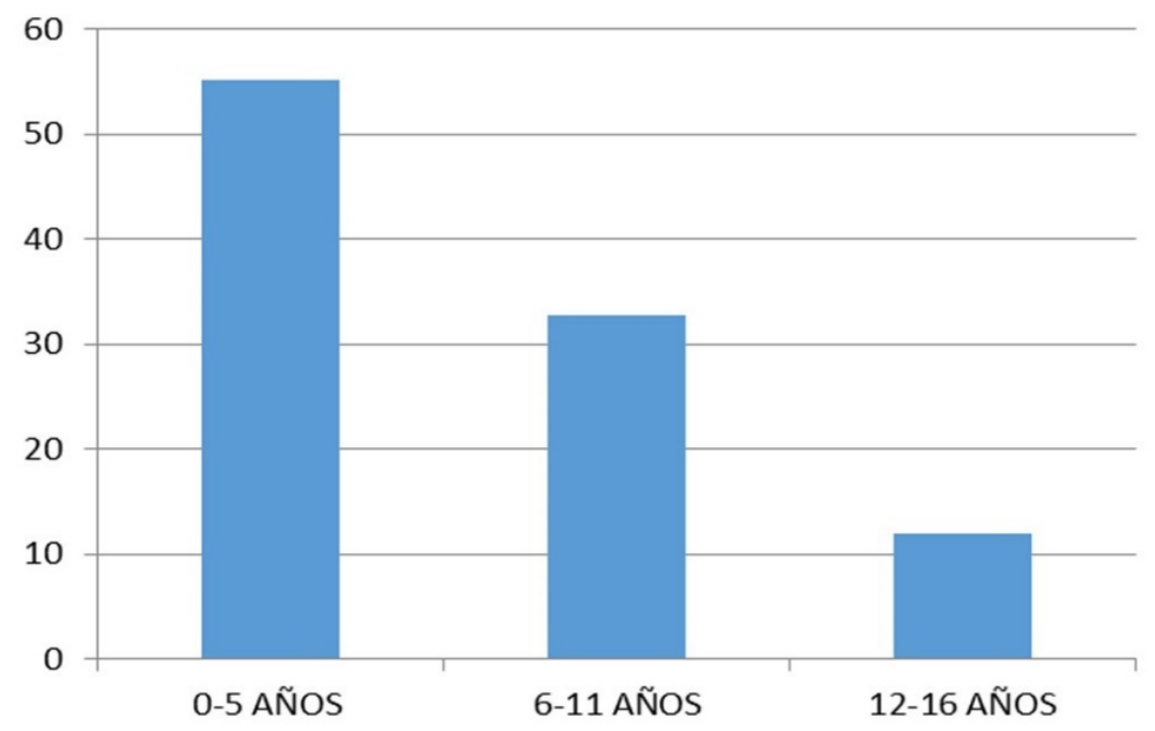

Fuente: IASS.

La configuración de la familia en origen, antes de iniciarse la emigración de los progenitores, nos permite intuir algunas claves para la posterior discusión. Uno de cada tres menores convivía en su país de origen (con o sin hermanos) con la familia extensa, en el momento de ser reagrupados. Otro tercio convivía con la madre y otro con la familia nuclear, que había sido reconstituida. Sólo un 6,9\% convivían con su padre (con o sin hermanos).

Una vez reagrupados, los menores que han sido atendidos por situaciones de riesgo conviven en Aragón en tres modelos de unidad familiar: con ambos progenitores $(39,2 \%)$, con su madre $(36,5 \%)$ o en una familia reconstituida por uno de sus progenitores $(17,6 \%)$. Las unidades constituidas por la familia extensa, guardadores o padres no alcanzan el 5,0\% cada una. Esto coincide con los informes que señalan que el rol de las mujeres en los procesos de reagrupación está más presente que el de los varones (Pedone et al., 2012). De hecho, son las madres las que forman mayoritariamente las nuevas familias reconstituidas (en el 84,6\% de los casos).

La mayoría de estos expedientes $(62,2 \%)$ se inician a propuesta de los Servicios Sociales (autonómicos, comarcales o municipales). Siendo uno de cada cinco notificantes algún cuerpo policial presente en Aragón. La situación que motiva la apertura de los expedientes puede estar vinculada al maltrato físico $(32,4 \%)$ o psicológico $(24,3 \%)$, que suman la mitad de los casos. En ese ámbito, la negligencia física (malnutrición, etc.) es un estadio previo, presente en el inicio de un cuarto de los expedientes. Un 8,1\% de los mismos reseñan conflictos en torno al modelo educativo o de crianza (incapacidad parental y falta de atención adecuada) y sólo se registró un expediente por violencia filio-parental (VFP). 
La mitad de estos expedientes, en el momento de realizar la investigación, estaban en situación de observación: indicando que los equipos asistenciales supervisan las dinámicas familiares, trabajando con los progenitores las pautas que mejoren la situación. Y un tercio implicaban una tutela firme por el gobierno aragonés, retirando al menor de su entorno familiar e incluyéndolo en un programa residencial, una vez que las medidas de supervisión han resultado insuficientes. Las guardas de menores, en los casos en que se otorgan a la familia extensa o a familias de acogida, son las menos comunes $(14,9 \%)$.

Una vez se inicia el expediente, las profesionales del SAIA intervienen con la familia $(67,0 \%)$, con el menor mediante terapia individual $(24,0 \%)$ o con ambos $(9,0 \%)$. Priman, por tanto, las intervenciones correctoras de aquellas dinámicas familiares que tienen consecuencias negativas como las que hemos señalado: maltrato o negligencia, tanto física como psicológica. Aunque estas se interrumpen cuando el menor alcanza la mayoría de edad (en el 35,0\% de los expedientes), sin que esto signifique que la integración en la familia haya resultado exitosa: otro riesgo que las entrevistas también señalan. Se trata de expedientes complejos, con los que deben intervenir diversos perfiles profesionales (trabajadoras sociales, psicólogas, etc.), y que implican intervenciones dilatadas en el tiempo. El 26,9\% de estos expedientes habían estado abiertos más de dos años, en el momento del estudio. Y la mitad estaban abiertos entre uno y dos años.

Esta misma complejidad y las dificultades en las relaciones familiares o de adaptación a las nuevas responsabilidades familiares que motivan la apertura de los expedientes de protección de menores, se reiteran en los expedientes de reforma: aquellos que reflejan la intervención socioeducativa con menores que han sido condenados por infracciones jurídicas. De acuerdo a la información facilitada por el Equipo de Medio Abierto del IASS, buena parte de los menores que son derivados a este servicio han tenido una relación previa con diferentes servicios sociales, durante periodos prolongados.

De forma que, según los entrevistados, estos expedientes señalan la necesidad de establecer medidas preventivas, coordinadas y tendentes a superar las dificultades de integración social y familiar no sólo de los menores, sino también de sus progenitores. Cuando los menores cometen infracciones, las relaciones familiares suelen estar ya muy deterioradas. Con roles parentales no adecuados y, en algunos casos, con la posibilidad de que la familia valore la repatriación del menor, como acaba ocurriendo en algunas ocasiones.

A la vista de los expedientes de reforma y del conjunto de las entrevistas, las variables que llevan más lejos los conflictos, tanto con la familia, como con el entorno social, pueden estar conectadas con:

a. Las expectativas previas de los menores: cuando hay pautas que priorizan el consumismo, bien en origen o bien en destino; $u$ otras influidas por la trayectoria escolar y/o laboral del menor en origen, etc.

b. La precariedad de la situación laboral de los progenitores en destino: con horarios incompatibles con la conciliación de la vida familiar; por la escasa renta disponible, etc. 
c. Una inserción escolar no adecuada: cuando se produce un desfase curricular entre la formación en origen y en destino; por la ausencia de la familia en los apoyos al proceso de adaptación al nuevo entorno escolar, etc.

d. Y los vínculos con grupos etario al margen de la autoridad familiar (bandas, etc.), en el caso de menores con infracciones más graves.

Los expedientes que, a modo de muestra, hemos examinado, señalan la intervención de diversos servicios, desde la infancia hasta la adolescencia de los menores. Todos ellos habían detectado conflictos dentro de la familia, y un alejamiento progresivo del menor respecto a los recursos universales, sobre todo los educativos. De forma que la coordinación de profesionales en espacios estables es clave para evitar que una aparente sobreintervención tenga resultados como los examinados.

Tensiones alrededor de la reagrupación

Los casos en los que la reagrupación de una menor deriva en una intervención correctora por parte de los servicios sociales o el sistema de justicia juvenil nos sirven para introducir los resultados sobre las dificultades más comunes detectadas por los profesionales. En primer lugar, los expedientes y las entrevistas analizadas señalan las dificultades previas a la reagrupación, derivadas de:

a. Las características de la familia en origen, atendiendo a cómo eran los vínculos afectivos y los modelos de crianza.

b. Las características de la familia en destino, especialmente por el rol del reagrupante dentro de la nueva familia (si esta es reconstituida); así como por las expectativas de los familiares reagrupantes respecto al menor.

c. La trayectoria vital del menor en origen (familiar, escolar, de relaciones con su grupo etario, etc.).

d. Y la trayectoria socioeconómica de la familia en destino.

Esta última, muy relacionada con la estabilidad o la precariedad laboral de los progenitores, la conciliación de la vida familiar y laboral, las relaciones con el entorno próximo o la percepción de movilidad social, entre otros factores, es común también a la etapa de la migración en la que el menor ya ha llegado al país de destino. En ese momento, las dificultades posteriores a la reagrupación implican retos para la estructura y la convivencia familiar, que se tensionan en torno a tres ejes:

a. Las características de las relaciones familiares: por la adecuación o no de los modelos educativos, por la presencia de un nuevo miembro en el hogar, por la distribución de las responsabilidades de la crianza entre los progenitores, etc.

b. La escolarización obligatoria y el éxito escolar, señalado como el factor determinante en la integración del menor.

c. Y la nueva trayectoria vital del menor en destino, generando relaciones con su (nuevo) grupo etario, etc. 


\section{2 implicaciones para las políticas públicas}

Las tensiones detectadas alrededor del proceso de reagrupación familiar de los menores extranjeros interrogan a las administraciones públicas con responsabilidades en este procedimiento. Pues, el análisis de las mismas indica que, de cara a un itinerario exitoso de integración en la sociedad de acogida, son necesarias nuevas estrategias con implicaciones evidentes en las políticas públicas. En este apartado las examinamos en dos bloques. Uno constituido por factores asociados al proceso migratorio. Otro que agrupa todo lo referente a la organización de los servicios públicos.

En primer lugar, los resultados nos indican la importancia de desarrollar acciones preventivas, tanto antes como después de la llegada de los niños, niñas y adolescentes. Estas acciones deberían centrarse en cuatro ejes. Uno dedicado a las relaciones familiares, en el que se desarrollen actividades específicas de acompañamiento a las familias (biológicas o reconstituidas), así como espacios de encuentro entre familias reagrupantes, en los periodos previos y posteriores a la llegada de los menores. Otro eje se conforma en torno a las acciones orientadas al apoyo técnico para una adecuada trayectoria vital del menor en la sociedad local de destino, incluyendo un acompañamiento individual, en tanto prestación técnica (Colegio Oficial de Trabajadores Sociales de Madrid - COTSM, 2003; Melero, 2010), y foros grupales donde concurran otros reagrupados del mismo grupo etario (infancia y adolescencia). Estos grupos podrían extenderse, de acuerdo con los recursos del territorio, a jóvenes adultos que fueron reagrupados como menores (Pedone et al., 2013), contando este eje siempre con la necesidad de caminar hacia la implementación o la coordinación con proyectos locales de mentoría social (Herrera, Dubois \& Grossman, 2013). Como tercer eje, profesionales y literatura coinciden en subrayar la importancia de un acompañamiento social durante la escolarización de los menores. Tanto individualmente, en coordinación con los servicios educativos que cada territorio despliega, como a través de la información a los progenitores, a los que es preciso apoyar al menos durante el primer año escolar, con sesiones grupales (Pastor y Martínez, 2014). Y, por último, como complemento necesario al apoyo en la escolarización, los resultados analizados apuntan a la facilitación de vías de acceso a un ocio inclusivo, como parte de las necesidades que los servicios sociales deben atender en su apoyo a menores y familias: centros juveniles, colonias y campamentos, asociacionismo, escultismo, etc. (Fraguela, De Juanas y Franco, 2018).

En segundo lugar, la evaluación y la innovación en cuanto a las estrategias de organización de los servicios implicados, deberían atender especialmente a los límites jurídicos y administrativos actuales, a la territorialización de los servicios y a la coordinación entre los mismos, así como a la formación de profesionales. En cuanto al marco jurídico, constatamos que el esfuerzo que realizan las familias de origen no comunitario para reunirse con sus descendientes (y ascendientes), es claramente diferente del que protagonizan las familias comunitarias. La barrera administrativa de la nacionalidad, como consecuencia implícita, se trasladaría al proceso de adaptación al territorio de destino, como reflejan los expedientes abiertos en Protección de Menores. En el caso estudiado, los menores de origen no comunitario suman dos tercios de estos expedientes, muy por encima de su peso dentro de esta franja de edad entre los menores extranjeros residentes. Entre ellos, coincidiendo con lo descrito por estudios de otros contextos (Gil, 2010), destaca la mayor presencia de 
intervenciones sobre familias latinoamericanas, por encima de su peso porcentual en la población de origen extranjero.

Al mismo tiempo, el análisis de expedientes y entrevistas señala dos fuentes principales de limitaciones administrativas a la integración, en tanto proceso bidireccional (Sayed, 2010). Por un lado, la información precisa para realizar los trámites administrativos no se encuentra disponible en el mismo grado en todo el territorio estudiado. La organización (provincial) del ministerio responsable de la Extranjería y la estructuración territorial de los gobiernos locales con competencias en esta materia imponen diferencias en la accesibilidad, vinculadas a la situación geográfica del municipio de residencia. Esto es especialmente importante, pues, como indican los profesionales, la provisión de información es la primera oportunidad de contacto con las familias (Pastor y Martínez, 2014). Por otro lado, el progresivo endurecimiento de los requisitos de nivel de renta familiar por parte de la actual legislación de Extranjería marca igualmente una clara diferencia entre familias de origen comunitario y no comunitario (González-Ferrer, 2014). Las primeras perciben que reunificar a los menores implica decisiones complejas, en el marco general un proyecto migratorio muy fragilizado por su actual situación económica (empleo precario, empleo sumergido o desempleo). Las segundas, además, deben "demostrarlo" a la Administración (en este caso, local y estatal). Como consecuencia, los servicios sociales y el tejido social detectan la presencia de familiares que, para superar la barrera del nivel de renta exigido por la legislación, han sido reagrupados fuera del marco establecido por la misma (Pedone et al., 2012). Este colectivo es especialmente vulnerable, tanto en el caso de adultos, como en el de menores.

Por lo que se refiere a las citadas limitaciones surgidas por la territorialización de los servicios, estas se complejizan cuando son afectadas por los desequilibrios internos de las sociedades de destino. Este es el caso de la Comunidad Autónoma estudiada, pero también de otras, en las que hay una distribución poblacional dual: con núcleos urbanos más poblados y municipios de baja densidad en el resto del territorio, a menudo con una elevada dispersión geográfica. Esto hace necesaria una adaptación de las propuestas de actividades preventivas a las necesidades de recursos humanos que los servicios sociales locales presentan, dotando de más personal a las estructuras territoriales y evitando pautas evaluadas como menos eficientes: como la presencia intermitente de profesionales itinerantes, o la adscripción de nuevas tareas preventivas, como la propuesta aquí, a los equipos ya existentes (Alemán y Soriano, 2013).

Otra de las mejoras que se infiere, en cuanto a la organización de los servicios implicados en la reagrupación, así como en otros procesos vinculados a la migración, es el diseño de estrategias estables de coordinación entre los mismos. En la línea de las actuales experiencias promovidas por los diferentes planes y estrategias (de gestión de la diversidad, hacia la interculturalidad, etc.), que buscan reordenar las políticas públicas que se habían desplegado para el periodo de la acogida, dentro de la anterior fase del ciclo migratorio, sería necesario incorporar la creación de mesas de trabajo específicas sobre reagrupación. Los profesionales coinciden en reclamar espacios técnicos estables, en los que se revise y coordine el funcionamiento de la intervención de las diversas Administraciones en torno a la reagrupación familiar, tanto de menores como de adultos (Pastor y Martínez, 2014).

Prospectiva. Revista de Trabajo Social e intervención social • No. $29 \bullet$ ene.-jun. $2020 \bullet$ pp. 151-172 e-ISSN: 2389-993X • Doi: 10.25100/prts.v0i29.8542 Universidad del Valle - Cali, Colombia 
Coincidiendo así con las propuestas implementadas desde el enfoque comunitario de la intervención social (Giménez, 2015).

Y, finalmente, desde el ámbito profesional también se demanda la incorporación de conocimientos y habilidades, a través de la formación específica. Unas competencias profesionales interculturales que resultan necesarias, tanto para avanzar en la definición de buenas prácticas en el acompañamiento al proceso administrativo y social analizado, como para renovar metodológicamente el Trabajo Social.

\section{Conclusiones}

Este artículo ha analizado la movilidad de menores a Europa, desde la perspectiva de la figura jurídica de la reagrupación familiar, en una Comunidad Autónoma situada en la frontera entre los estados francés y español. Ha llegado a la conclusión de que los servicios sociales de las administraciones locales tienen un rol que resulta clave para la integración de estos adolescentes y niños. En primer lugar, porque cuentan con experiencias exitosas y transferibles en su mismo nivel administrativo, para acompañar a las familias y a los propios menores, tanto antes como después de la migración.

En segundo lugar, porque son las entidades públicas más próximas a los reagrupantes, sean comunitarios (ciudadanos de la Unión Europea) o extracomunitarios. Y el acceso a los programas preventivos, según se ha analizado, es un elemento que influye de forma significativa en el desarrollo posterior de esta movilidad, siendo necesario que la implementación de estos programas esté adaptada al territorio, tanto como a las características socioeconómicas de esta modalidad migratoria. Hasta el punto de que hay nacionalidades como la china que, conformando un porcentaje elevado de las solicitudes de reagrupación, apenas recurren a los servicios sociales especializados que asesoran en este proceso.

En tercer lugar, los discursos profesionales convergen con las propuestas académicas de introducir el acompañamiento social como una prestación técnica del Trabajo Social. Previamente a la reagrupación, como vía de incorporación de los progenitores al itinerario. Así como a partir de la llegada del menor, ofreciendo a la familia participar en las actividades grupales e individuales, evaluadas como buenas prácticas.

Finalmente, en este artículo, asumiendo el enfoque comunitario del Trabajo Social, proponemos que los programas de acompañamiento se desarrollen a partir de un diseño participado, en espacios de coordinación interadministrativa. Esta relación técnica debe incluir el acceso regular a los datos sobre las solicitudes de reagrupación, con el fin de mejorar y adaptar la intervención preventiva que se propone, generando así diagnósticos compartidos, que permitan, por una parte, evolucionar las prácticas profesionales y los protocolos y, por otra, conocer los cambios recientes de esta movilidad, como ocurre con los nuevos roles de la mujer, en tanto reagrupante o reagrupada. 


\section{Referencias bibliográficas}

Alemán, C., y Soriano, R. (2013). Servicios Sociales e Inmigración en tiempos de crisis económica. En E. Aja, J. Arango y J. Oliver (Eds.), Inmigración y crisis entre la continuidad y el cambio. Anuario de la inmigración en España (pp. 90-113). Barcelona, España: CIDOB.

Aparicio, R., y Tornos, T. (2006). Hijos de inmigrantes que se hacen adultos. Madrid, España: Ministerio de Trabajo y Asuntos Sociales.

Blanco, C. (2016). Familias transnacionales y Derechos Humanos. Reflexiones sobre el derecho a la reagrupación en España. Deusto Journal of Human Rights, (1), 77-104. doi: 10.18543/djhr-1-2016pp77-104.

Brey, E., \& Stanek, M. (2013). The Impacts of Restrictions and Entitlements on the Integration of Family Migrants: National Report, Spain. Gran Bretaña: IMPACIM. Universidad Complutense de Madrid.

Colegio Oficial de Trabajadores Sociales de Madrid - COTSM. (2003). Manual para el trabajo social de acompañamiento en los itinerarios de inserción. Madrid, España: COTSM.

Díaz, L., Gómez, E., \& Ricart, S. (2019). Bones pràctiques municipals: 2014-2018. Barcelona, España: Fundació Carles Pi i Sunyer d'estudis autonòmics i locals.

Domingo, A., León, P., y García, J. (2009). El reagrupament familiar a la província de Barcelona, 2004-2006: trets demogràfics i disribució territorial. Documents d'anàlisi Geogràfica, (54), 55-78.

ECRI. (2018). Informe de la ECRI sobre España. (Quinto ciclo de supervisión). Estrasburgo, Francia: European Commission against Racism and Intolerance.

Foro para la Integración Social de los Inmigrantes - FISI (2017). Informe anual sobre el estado de situación de la integración de los inmigrantes y refugiados en España. Madrid, España: Ministerio de Trabajo, Migraciones y Seguridad Social.

Fraguela, R., De Juanas, A., y Franco. R. (2018). Ocio deportivo en jóvenes potencialmente vulnerables: beneficios percibidos y organización de la práctica. Pedagogía Social. Revista Interuniversitaria, (31), 49-58. doi: 10.7179/PSRI_2018.31.04.

Gil, S. (2010). Políticas migratorias y relaciones bilaterales España-América Latina. En G. Pinyol, y A. Ayuzo. (Coords.), Inmigración latinoamericana en España: el estado de la investigación (pp. 93-118). Barcelona, España: CIDOB.

Giménez, C. (2004). Servicio de Mediación Social Intercultural. RES. Revista de Educación Social, (2), s.p. Recuperado de http:/ / www.eduso.net/res/ ?b=4\&c=28\&n=86.

Giménez, C. (Coord.). (2015). Juntos por la convivencia. Claves del Proyecto de Intervención Comunitaria Intercultural. Metodología. Barcelona, España: Obra Social La Caixa. 
Gimeno-Monterde y Gutiérrez-Sánchez

Glick, N., \& Salazar, N.B. (2013). Regimes of Mobility across the Globe. Journal of Ethnic and Migration Studies, 2(39), 183-200. doi: 10.1080/1369183X.2013.723253.

González-Ferrer, A. (2009). La reagrupación familiar en España. Algunas cifras para el debate. En E. Aja, J. Arango, y J. Oliver (Eds.), La inmigración en tiempos de crisis. Anuario de la inmigración en España (pp. 120-137). Barcelona, España: CIDOBBellaterra.

González-Ferrer, A. (2014). La inmigración por motivos familiares durante la crisis. Anuario $C I D O B$ de la Inmigración. Recuperado de https://www.cidob.org/articulos/anuario_cidob_de_la_inmigracion/2014/la_i nmigracion_por_motivos_familiares_durante_la_crisis.

Guerraoui, Z., \& Sturm, G. (2012). Familles migrantes, familles en changement. Le paradigme de la complexité. L'exemple des familles d'origine maghrébine. Devenir, 24(4), 289-299. doi: 10.3917/ dev.124.0289.

Herrera, C., Dubois, D.L., \& Grossman, J.B. (2013). The role of risk. mentoring experiences and outcomes for youth with varying risk profiles. New York, Estados Unidos: PublicPrivate Ventures project distributed by MDRC.

Hervías, V. (2014). Políticas migratorias y dificultades de género en los reagrupamientos familiares. Investigaciones Feministas, 5, 390-415. doi: 10.5209/rev_INFE.2014.v5.48301.

Jefatura del Estado de España. (11 de diciembre de 2009). Reforma de la Ley Orgánica 4/2000, sobre derechos y libertades de los extranjeros en España y su integración social. [Ley orgánica 2 de 2009]. BOE-A-2009-19949.

Malgesini, G., y Giménez, C. (1997). Guía de conceptos sobre migraciones, racismo e interculturalidad. Madrid, España: Los Libros de la Catarata.

Melero, L. (2010). La persona más allá de la migración, manual para la intervención psicosocial con personas migrantes. Valencia, España: CeiMigra.

Mestre, R. (2005). Trabajadoras de cuidado, las mujeres en la ley de extranjería. En F. Checa (Ed.), Mujeres en el camino, El fenómeno de la migración femenina en España (pp. 139-168). Barcelona, España: Icaria.

Miguélez, F., y López, P. (2014). Crisis, empleo e inmigración en España. Un análisis de las trayectorias laborales. Barcelona, España: Bellaterra.

Moreno, S., y De Alós, R. (2016). La inmigración en España: ¿Una integración con pies de barro? Política y Sociedad, 53(2), 509-528. doi: 10.5209/rev_POSO.2016.v53.n2.48312.

Novales, A. (2015). La reintegración de menores en las familias inmigrantes. Riesgos y necesidades de los menores inmigrantes reagrupados. Cuadernos de Trabajo Social, 28(2), 235-243. doi: 10.5209/rev_CUTS.2015.v28.n2.44874. 
Gimeno-Monterde y Gutiérrez-Sánchez

Pastor, E., y Martínez, B.J. (2014). Análisis de las realidades de los procesos de reagrupación familiar y las respuestas de los servicios municipales. Acciones e investigaciones sociales, (34), 27-55. doi: 10.26754/ojs_ais/ais.201434910.

Pedone, C. (2008). “Varones aventureros" vs. "Madres que abandonan”: Reconstrucción de las relaciones familiares a partir de la migración ecuatoriana. Revista Interdisciplinar da Mobilidade Humana, 16(30), 45-64.

Pedone, C., Agrela, B., y Gil, S. (2012). Políticas públicas, migración y familia. Una mirada desde el género. Papers, Revista de Sociología, 97(3), 541-568. doi: 10.5565/rev/papers/v97n3.412.

Pedone, C., Gómez, C., Sardà, A., \& Llobet, L. (2013). Avaluació del Programa d'Acompanyament al reagrupament familiar a Barcelona. Barcelona, España: Institut Infancia i Món Urbà.

Quintero, J.D., y Fernández, C. (2014). Familias inmigrantes en España: estructura sociodemográfica, roles de género y pautas culturales de los hijos adolescentes. Papeles de población, 20(80), 87-118.

Ramo, M.C., y Meléndez, I. (2012). Adolescentes inmigrantes: del relato a la singularidad. Zaragoza, España: Mira.

Sánchez, M. (2018). Programa noves famílies: acompanyament al reagrupament familiar. Banc d'experiències $i$ bones pràctiques. Barcelona, España: Direcció de Serveis d'Immigració i Interculturalitat, Ajuntament de Barcelona.

Sayed, N. (2010). Experiencia de migración y salud mental, hacia un nuevo modelo de salud. En L. Melero (Ed.), La persona más allá de la migración, manual para la intervención psicosocial con personas migrantes (pp. 259-295). Valencia, España: CeiMigra.

Shamir, R. (2005). Without borders? Notes on globalization as a mobility regime. Sociological Theory, 23(2), 197-217. doi: 10.1111/j.0735-2751.2005.00250.x.

Vacchiano, F. (2018). Desiring mobility. Children's migration, parents' distress and constraints on the future in North Africa. En J. Bhabha, J. Kanics, \& D. Senovilla (Eds.), Research Handbook on Child Migration (pp. 82-97). Londres, Gran Bretaña: Edward Elgar Publishing. 


\section{OTROS ARTÍCULOS DE PROSPECTIVA No. 29 DE 2020}

EDITORIAL

La Reconceptualización: una opción a la encrucijada del Trabajo Social en Colombia Víctor Mario Estrada-Ospina

\section{ARTÍCULOS}

Formación profesional y la práctica supervisada en el Servicio Social brasileño

Reginaldo Ghiraldelli

El rol docente del tutor y supervisor de prácticas de Trabajo Social: construcción de la reflexividad y el compromiso durante la formación a través de la supervisión

Carmina Puig-Cruells

Problematizando las prácticas preprofesionales en Trabajo Social. Desafios y perspectivas

Ruth Noemí Parola

Trabajo Social en contextos de formación política: la práctica transformadora

Angélica López-Yepes

Jackeline Cuenca-Echeverry

Investigación cuantitativa en una práctica universitaria de intervención en comunidad en el norte de México

Adán Cano-Aguilar
Interventores y comunidades vulnerables: una propuesta de formación para universitarios

Dulce Nayeli Cohetero-Hernández

Fidel González-Quiñones

Reagrupación familiar de menores en Aragón. Propuestas de acompañamiento en el proceso migratorio

Chabier Gimeno-Monterde

José David Gutiérrez-Sánchez

Aportaciones de la Educación en Derechos Humanos (EDH) y la Investigación Acción Participativa (IAP) en contextos de trabajo comunitario

Carla Cubillos-Vega

Condiciones para una NeoReconceptualización del Trabajo Social en Chile, Latinoamérica y el Caribe

Luis Vivero-Arriagada

Justicia sin daño: una apuesta por el fortalecimiento del acceso a la justicia Diego Fernando Acosta-Daza

\section{IN MEMORIAM}

Camilo Bautista Ochoa, un santandereano que se enamoró del Pacífico

Jesús Glay Mejía-Naranjo

\section{PROSPECTIVA}

Revista de Trabajo Social e Intervención Social 